\title{
Desempenho de suínos em terminação alimentados com diferentes níveis de restrição alimentar e de energia na dieta*
}

\section{Performance of pigs in finishing period fed with different levels of feed restriction level and of energy in the diet}

\author{
Helomar Cristina Almeida Barbosa:" Antonio Assis Vieira, ${ }^{\star \star \star}$ Zoroastro Soares Teixeira, ${ }^{\star \star \star \star}$ \\ Fernando Queiroz de Almeida, ${ }^{\star \star \star}$ Joaquim Ferreira Campos ${ }^{\star \star \star \star \star}$
}

\begin{abstract}
Resumo
O objetivo deste trabalho foi avaliar diferentes níveis de restrição alimentar e níveis de energia dietética sobre desempenho de suínos em terminação. Foram utilizados 720 suínos Dalland, 360 machos castrados e 360 fêmeas, distribuídos em delineamento experimental de blocos casualizados em arranjo fatorial, com quatro níveis de restrição alimentar, dois níveis de energia líquida (EL), dois sexos e três blocos. Os níveis de restrição alimentar utilizados foram: 15,10 e $5 \%$ da alimentação à vontade $(0 \%)$ e os níveis dietéticos de energia foram de 2.083 e $2.252 \mathrm{Kcal}$ de energia líquida por $\mathrm{kg}$ de dieta. As rações foram formuladas à base de sorgo, farelo de soja e farelo de trigo. Foram avaliados o consumo de ração, ganho de peso diário, conversão alimentar, consumo de energia líquida, conversão de energia líquida e espessura média de toucinho. Os resultados obtidos mostraram redução do ganho de peso com aumento no nível de restrição alimentar sem afetar a conversão alimentar e redução na espessura de toucinho. O aumento no nível dietético de EL resultou em aumento no ganho de peso e melhoria na conversão alimentar e aumento na espessura de toucinho. Os machos castrados e fêmeas apresentaram ganho de peso semelhantes.
\end{abstract}

Palavras-chave: conversão alimentar, energia líquida, ganho de peso.

\begin{abstract}
The purpose these research was to evaluate the effect of different levels of feed restriction and net energy in the diet on the performance of pigs in the finishing period. It was used 720 animals Dalland, 360 barrows and 360 gilts, distributed in factorial randomized block design, with four levels of feed restriction feed restriction, two levels of net energy (NE) and Sex, in three blocks The levels of feed restriction feed restriction were: $15,10 \%, 5$ of the ad libitum feed intake $(0 \%)$, and the levels of energy were 2083 and $2252 \mathrm{kcal} \mathrm{NE} / \mathrm{kg}$ of feed. The diets were formulated based on sorghum, soybean and wheat meal. The feed intake, daily weight gain, feed conversion, NE intake, efficiency of energy utilization, backfat thickness were evaluated. The results showed a reduction of the daily weight gain with increase in the level of feed restriction without affecting feed conversion and reduction in backfat thickness. The higher level of NE in the diet resulted in higher weight gain and better feed conversion and increase in the backfat thickness. The barrows and gilts had similar weight gain. The gilts had superior carcass quality than the barrows.
\end{abstract}

Keywords: daily weight gain, feed conversion, net energy.

\section{Introdução}

Os produtores de suínos têm sido remunerados pelo peso dos animais e bonificados pelo percentual de carne magra na carcaça, estimado a partir da espessura de toucinho. A produção de carcaças suínas com a qualidade exigida pelo mercado atual requer a utilização de programa alimentar adequado.

A restrição alimentar pode ser um instrumento adequado para melhorar a eficiência alimentar e reduzir a deposição de gordura; entretanto, não se equivale ao melhoramento genético na obtenção de animais mais eficientes na transformação de alimentos e com carcaças mais magras (Carnino, 1994), sendo, neste caso, mais um artifício para se alcançar tal objetivo. Além disto, animais que passam por programas de restrição alimentar têm necessidade de menor quantidade de alimento para deposição de proteína, ou seja, tem maior eficiência de deposição de proteína, em relação a animais que se alimentam à vontade (Leymaster e Mersmann, 1991).

À medida que se amplia a restrição alimentar dos animais, observa-se melhoria na conversão alimentar e redução no teor de gordura na carcaça, comparando-se com animais alimentados à vontade (Leymaster e Mersmann, 1991). Consi-

\footnotetext{
* Parte da Dissertação de Mestrado do primeiro autor em Zootecnia, UFRRJ.

* Zootecnista, Mestre em Zootecnia, bolsista da FAPERJ helobarbosa@bol.com.br

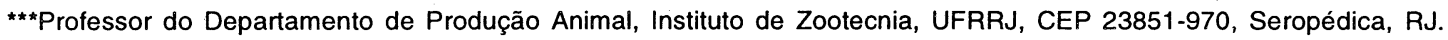

****Consultor Técnico, Fazenda Penalva, Sena Consultoria, CEP 37701-396, Poços de Caldas, MG.

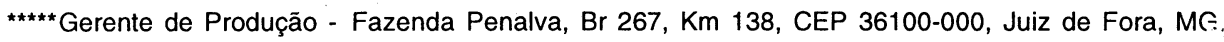


derando a restrição alimentar de até $15 \%$ em relação ao consumo à vontade, a tendência é a melhoria na eficiência de utilização dos alimentos pelos suínos. Além disto, com restrição alimentar de até $15 \%$ em relação ao consumo à vontade, há uma tendência de melhoria na eficiência de utilização dos nutrientes dos alimentos pelos suínos, o que não pode ser afirmado para restrições mais severas (Haydon et al., 1989).

O conteúdo de energia da dieta exerce grande influência sobre o consumo alimentar dos animais. Para animais alimentados à vontade, o aumento da ingestão de energia ingerida durante a fase de terminação, provavelmente, excede a exigência para máxima deposição de proteína, resultando em aumento na espessura de toucinho (Giles, 1990). Segundo Carnino (1994), quando o consumo de energia é alto, muito além da necessidade para síntese protéica ótima, ocorre aumento na quantidade de gordura depositada, aumentando a participação da energia para esta função, com tendência de piorar a conversão alimentar.

O consumo excessivo de energia que pode ocorrer na fase de terminação dos suínos alimentados à vontade pode ser evitado pela restrição de fornecimento de energia. Giles (1990) cita como forma de restrição alimentar, a redução na densidade energética da dieta durante a fase de terminação, evitando-se o excesso de gordura na carcaça, particularmente nas fêmeas.

Geralmente, os valores de energia nas dietas de suínos são expressos na forma de energia digestível (ED), energia metabolizável ( $E M)$ e energia líquida ( $E L)$, considerando-se os sistemas de avaliação de dietas, determinação das exigências energéticas e da predição do conteúdo energético de alimentos e dietas (Noblet e Henry, 1993).

A EL representa a melhor estimativa do verdadeiro valor energético de uma dieta e, o uso da EL permite que as exigências de energia e os valores energéticos da dieta sejam expressos em uma mesma base, independentemente da dieta, de forma que permite maior precisão nas estimativas do desempenho dos animais (Noblet, 1995).

Com base nestas observações, o presente trabalho teve como objetivo avaliar diferentes níveis de restrição alimentar e níveis de energia líquida da dita sobre o desempenho de suínos na fase de terminação.

\section{Material e métodos}

J experimento foi conduzido no seríodo de setembro a novemoro de 1998 e os animais utilizados no experimento selecionados no período de julho a agosto, sendo utilizados 720 suínos Dalland, 360 machos zastrados e 360 fêmeas, deszendentes de machos da linhagem Dalboar 70 , cruzados com fêmeas da linhagem C40.

*Energia metabolizável
Os animais foram separados por peso, idade e sexo para formação de blocos e alojados em dois galpões de terminação com 40 baias por galpão, sendo que em um dos galpões foram utilizadas 32 baias e, no outro, 16 baias. Foram alojados 15 animais/baia, sendo as baias dotadas de comedouro de alvenaria do tipo calha, com 10 bocas, situado à frente da baia e bebedouro tipo chupeta, situado ao fundo.

As rações experimentais foram fareladas, compostas por sorgo, farelo de soja e farelo de trigo para aquelas com nível de energia líquida de $2.083 \mathrm{Kcal} \mathrm{EL/kg}$ de ração (Tabela 1) e, compostas por sorgo, farelo de soja e óleo degomado para aquelas com nível de energia de $2.252 \mathrm{Kcal} E L / \mathrm{kg}$ de ração (Tabela 2), ambas suplementadas com minerais e vitaminas, de acordo com as recomendações do NRC (1998) para a suínos em terminação. Os níveis de restrição alimentar utilizados foram de $15 \%$ do consumo à vontade, $10 \%$ do consumo à vontade, $5 \%$ do consumo à vontade e $0 \%$ (alimentação à vontade). A quantidade de ração do consumo à vontade foi estimada com base em um pré-experimento, o qual permitiu determinar um consumo máximo de $3,200 \mathrm{~kg}$ de ração por animal por dia.

O conteúdo energético das dietas, expresso em Kcal EL/Kg de ração foi estimado pela proporção de $67 \%$ da EM, segundo valores médios descritos por Noblet et al. (1994).

As rações foram calculadas de modo que os animais submetidos a diferentes níveis de restrição alimentar e energia consumissem as mesmas quantidades de lisina e proteína bruta.

A alimentação dos animais foi feita de acordo com o manejo da granja, com as alterações propostas para cada tratamento, tendo sido a ração colocada à disposição durante 24 horas por dia para os animais alimentados à vontade.

Tabela 1 - Composição percentual da ração com nível de energia líquida (EL) de 2083kcal EL/kg de ração nos níveis de restrição alimentar para machos e fêmeas

\begin{tabular}{|c|c|c|c|c|c|c|c|c|}
\hline \multirow[b]{3}{*}{ Ingredientes } & \multicolumn{8}{|c|}{ Restrição alimentar (\%) } \\
\hline & \multicolumn{2}{|c|}{0} & \multicolumn{2}{|c|}{5} & \multicolumn{2}{|c|}{10} & \multicolumn{2}{|c|}{15} \\
\hline & $M$ & $F$ & $\bar{M}$ & $F$ & $\bar{M}$ & $F$ & $\bar{M}$ & $F$ \\
\hline Sorgo & 71,85 & 69,78 & 71,26 & 69,10 & 70,66 & 68,28 & 69,84 & 67,47 \\
\hline Farelo de soja & 17,30 & 21,00 & 18,80 & 22,60 & 20,40 & 24,50 & 22,30 & 26,60 \\
\hline Farelo de trigo & 8,20 & 6,60 & 7,20 & 5,60 & 6,10 & 4,40 & 4,90 & 3,00 \\
\hline Calcário & 0,97 & 0,94 & 0,94 & 0,91 & 0,90 & 0,87 & 0,86 & 0,82 \\
\hline Fosfato bicálcico & 1,08 & 1,09 & 1,18 & 1,19 & 1,29 & 1,30 & 1,41 & 1,42 \\
\hline Sal & 0,35 & 0,35 & 0,37 & 0,37 & 0,39 & 0,40 & 0,42 & 0,43 \\
\hline Premix Mineral & 0,23 & 0,23 & 0,23 & 0,23 & 0,23 & 0,23 & 0,23 & 0,23 \\
\hline Colina & 0,02 & 0,01 & 0,02 & 0,01 & 0,03 & 0,02 & 0,04 & 0,03 \\
\hline Total & 100,00 & 100,00 & 100,00 & 100,00 & 100,00 & 100,00 & 100,00 & 100,00 \\
\hline \multicolumn{9}{|c|}{ Composição calculada } \\
\hline Proteína bruta (\%) & 15,88 & 17,11 & 16,35 & 17,65 & 16,87 & 18,24 & 17,45 & 18,90 \\
\hline EL (Kcal/kg) & 2083 & 2083 & 2083 & 2083 & 2083 & 2083 & 2083 & 2083 \\
\hline $\mathrm{EM}^{*}(\mathrm{Kcal} / \mathrm{kg})$ & 3108 & 3117 & 3112 & 3121 & 3116 & 3125 & 3120 & 3130 \\
\hline EL (\% de EM) & 67,00 & 67,80 & 66,80 & 66,70 & 66,80 & 66,70 & 66,80 & 66,50 \\
\hline Cálcio total (\%) & 0,75 & 0,75 & 0,77 & 0,77 & 0,78 & 0,78 & 0,80 & 0,80 \\
\hline Fósforo total (\%) & 0,60 & 0,60 & 0,62 & 0,62 & 0,63 & 0,63 & 0,65 & 0,65 \\
\hline Lisina dgestived (\%) & 0,63 & 0,71 & 0,66 & 0,75 & 0,70 & 0,79 & 0,74 & 0,84 \\
\hline Lisina total (\%) & 0,72 & 0,81 & 0,76 & 0,86 & 0,80 & 0,90 & 0,84 & 0,96 \\
\hline
\end{tabular}


Para os animais com alimentação restrita, a ração foi colocada à disposição até o consumo total. Nas baias dos animais alimentados à vontade, as sobras de ração foram retiradas $e$ pesadas diariamente, pela manhã, antes do fornecimento de ração aos animais, para posterior cálculo do consumo médio diário e total de ração. Os animais tiveram livre acesso a água de boa qualidade, à vontade, durante todo o período experimental.

Durante o período experimental, os animais de cada baia foram pesados em grupo e em jejum, pela manhã, a cada sete dias, sempre no mesmo horário do dia. Ao atingirem o peso médio aproximado de $95 \mathrm{~kg}$, cinco animais de cada baia foram separados e enviados para abate e avaliação de espessura de toucinho totalizando, portanto, 240 animais. Os animais foram abatidos após jejum de 24 horas de ração e 12 horas de jejum de água. As carcaças foram separadas em duas metades por um corte longitudinal na linha dorsolombar. A espessura de toucinho foi mensurada com paquímetro, em três regiōes específicas, sendo a primeira medida feita na altura da primeira vértebra torácica, a segunda medida na altura da última vértebra torácica e a terceira na altura da última vértebra lombar, de acordo com a metodologia do Sistema de Tipificação de Carcaça Suína (Ministério da Agricultura, 1981). Foram avaliados o consumo de ração, ganho de peso diário, conversão alimentar, consumo de energia líquida, conversão de energia líquida, espessura de toucinho.

$O$ delineamento experimental utilizado foi de blocos ao acaso, sendo os tratamentos arranjados em esquema fatorial $4 \times 2 \times 2$ (níveis de restrição alimentar $x$ níveis de energia $x$ sexo), em três blocos. Para a formação dos blocos, foi considerado o peso dos animais no início do período experimental, sendo a unidade experimental representada pela baia.

Os valores médios dos parâmetros foram submetidos à análise de variância para avaliar os efeitos dos níveis de energia da dieta e de sexo e análise de regressão para níveis de restrição alimentar, utilizando o programa SAEG - Sistema de Análises Estatísticas e Genéticas (UFV, 1993).

\section{Resultados e discussão}

Não foi observada interação significativa entre os níveis de restrição alimentar, níveis de energia na dieta e sexo, exceto para a conversão alimentar, em que houve interação entre os níveis de energia dietéticos e sexo, para os parâmetros avaliados.

Os resultados de desempenho dos suínos em terminação em função da restrição alimentar são apresentados na Tabe-

Tabela 2 - Composição percentual da ração com o nível de energia líquida (EL) de 2252kcal EL/kg de ração nos níveis de restrição alimentar para machos e fêmeas

\begin{tabular}{|c|c|c|c|c|c|c|c|c|}
\hline \multirow[b]{3}{*}{ Ingredientes } & \multicolumn{8}{|c|}{ Restrição alimentar(\%) } \\
\hline & \multicolumn{2}{|c|}{0} & \multicolumn{2}{|c|}{5} & \multicolumn{2}{|c|}{10} & \multicolumn{2}{|c|}{15} \\
\hline & $M$ & $\mathrm{~F}$ & $M$ & $\mathrm{~F}$ & $M$ & $F$ & $M$ & $\mathrm{~F}$ \\
\hline Sorgo & 76,27 & 73,37 & 76,11 & 70,88 & 73,90 & 68,19 & 66,38 & 64,98 \\
\hline Farelo de soja & 17,10 & 19,80 & 17,10 & 21,90 & 18,90 & 24,20 & 25,70 & 26,90 \\
\hline Óleo degomado & 3,70 & 3,90 & 3,70 & 4,20 & 4,00 & 4,50 & 4,80 & 4,90 \\
\hline Calcário & 0,76 & 0,76 & 0,74 & 0,74 & 0,73 & 0,73 & 0,71 & 0,70 \\
\hline Fosfato bicálcico & 1,39 & 1,37 & 1,49 & 1,46 & 1,59 & 1,55 & 1,66 & 1.66 \\
\hline Sal & 0,39 & 0,39 & 0,41 & 0,42 & 0,44 & 0,44 & 0,47 & 0,47 \\
\hline Premix Mineral & 0,23 & 0,23 & 0,23 & 0,23 & 0,23 & 0.23 & 0,23 & 0,23 \\
\hline Colina & 0,05 & 0,04 & 0,06 & 0,04 & 0,06 & 0,04 & 0,05 & 0,06 \\
\hline L-lisina & 0,11 & 0,14 & 0,16 & 0,13 & 0,15 & 0,12 & - & 0,10 \\
\hline Total & 100,00 & 100,00 & 100,00 & $1.00,00$ & 100,00 & 100,00 & 100,00 & 100,00 \\
\hline \multicolumn{9}{|c|}{ Composição calculada } \\
\hline Proteína bruta (\%) & 14,5 & 15,98 & 15,00 & 16,71 & 15,63 & 17,53 & 17,94 & 18,44 \\
\hline $\mathrm{EL}(\mathrm{Kcal} / \mathrm{kg})$ & 2252 & 2252 & 2252 & 2252 & 2252 & 2252 & 2252 & 2252 \\
\hline $\mathrm{EM}^{*}(\mathrm{Kcal} / \mathrm{kg})$ & 3412 & 3415 & 3406 & 3424 & 3414 & 3435 & 3442 & 3447 \\
\hline EL (\% de EM) & 66,00 & 65,90 & 66,10 & 65,80 & 66,00 & 65,60 & 65,40 & 65,30 \\
\hline Cálcio total (\%) & 0,74 & 0,74 & 0,76 & 0,76 & 0,78 & 0,79 & 0,81 & 0,81 \\
\hline Fósforo total (\%) & 0,59 & 0,59 & 0,61 & 0,61 & 0,63 & 0,64 & 0,66 & 0,66 \\
\hline Lisina digestivel (\%) & 0,69 & 0,77 & 0,71 & 0,81 & 0,75 & 0,86 & 0,80 & 0,91 \\
\hline Lisina total (\%) & 0,76 & 0,87 & 0,80 & 0,91 & 0,85 & 0,96 & 0,91 & 1,00 \\
\hline
\end{tabular}

la 3. Não foram observados efeitos significativos $\left(\mathrm{P}^{3} 0,05\right)$ dos níveis de restrição alimentar sobre o peso final, conversão alimentar, peso e comprimento de carcaça, conversão de energia líquida em peso corporal, enquanto o consumo médio de ração diário, ganho de peso médio diário, espessura média de toucinho, consumo de energia líquida apresentaram resposta linear decrescente $(P<0,05)$, em função do aumento no nível de restrição alimentar. 
Tabela 3 - Desempenho de suínos em terminação em função do nível de restrição alimentar

\begin{tabular}{|c|c|c|c|c|c|c|c|}
\hline \multirow{2}{*}{ Parâmetro } & \multirow{2}{*}{ Unidade } & \multicolumn{4}{|c|}{ Niveis de restrição alimentar (\%) } & \multirow{2}{*}{ Média } & \multirow{2}{*}{$\begin{array}{l}\text { CV } \\
(\%)\end{array}$} \\
\hline & & 0 & 5 & 10 & 15 & & \\
\hline Peso inicial & $\mathrm{kg}$ & 58,00 & 57,82 & 58,64 & 58,11 & 58,14 & 5,51 \\
\hline Peso final & $\mathrm{kg}$ & 94,43 & 93,88 & 94,27 & 92,73 & 93,82 & 3,29 \\
\hline Consumo médio de ração & $\mathrm{kg} / \mathrm{d}$ & 2,85 & 2,78 & 2,71 & 2,54 & 1 & 7,17 \\
\hline Ganho de peso médio & $\mathrm{kg} / \mathrm{d}$ & 0,97 & 0,95 & 0,93 & 0,88 & 2 & 8,50 \\
\hline Conversão alimentar & $\mathrm{kg} / \mathrm{kg}$ & 2,93 & 2,94 & 2,94 & 2,89 & 2,92 & 5,11 \\
\hline Consumo de energia líquida & $\mathrm{kcal} / \mathrm{d}$ & 6165,83 & 6043,63 & 5882,24 & 5508,97 & 3 & 7,17 \\
\hline Conversão de energia & $\mathrm{kcal} / \mathrm{kg}$ & 6348,26 & 6366,59 & 6356,92 & 6265,69 & 6334,36 & 5,20 \\
\hline Espessura média de toucinho & $\mathrm{cm}$ & 2,59 & 2,44 & 2,42 & 2,41 & 4 & 5,40 \\
\hline
\end{tabular}

* Significativo $(P<0,05)$ pelo teste $t$

i $\hat{Y}=2,87-0,02 R A\left(R^{2}=0,94\right)^{2} \hat{Y}=0,976-0,0058 R A\left(R^{2}=0,94\right)^{3} \hat{Y}=6220-42,639 R A\left(R^{2}=0,93\right) \quad 4 \hat{Y}=2,549-0,0112 R A\left(R^{2}=0,73\right)$

O consumo médio diário de ração diminuiu linearmente com o aumento no nível de restrição alimentar, conforme Figura 1.Esses resultados são discordantes daqueles obtidos por Donker et al. (1986) que, avaliando machos inteiros, machos castrados e fêmeas suínas, observaram que o consumo de ração diário foi semelhante para os animais alimentados à vontade e em restrição alimentar, ou seja, os animais não atingiram o consumo máximo do nível de alimentação à vontade, sendo, portanto, a quantidade consumida à vontade semelhante a quantidade proposta no nível de restrição alimentar.

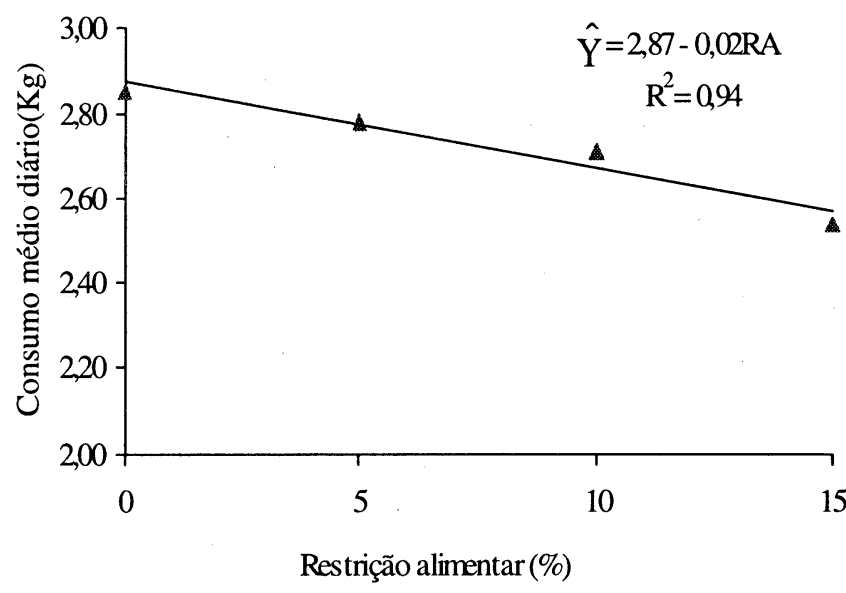

Figura 1 - Consumo médio diário de suínos em terminação em função do nivel de restrição alimentar

Em relação ao ganho de peso médio diário (Figura 2) estes resultados estão de acordo com aqueles obtidos por Quiniou et al. (1996), que, avaliando quatro níveis de restrição alimentar: $30,20,10 \%$ do consumo à vontade $(0 \%)$, observaram que o aumento no consumo resulta em aumento linear no ganho de peso médio diário de suínos. Resultados semelhantes também foram obtidos por Bikker et al. (1996) e Ellis et al. (1996), restrição alimentar: $30,20,10 \%$ do consumo à vontade $(0 \%)$, observaram que o aumento no consumo resulta em aumento linear no ganho de peso médio diário de suínos. Resultados semelhantes também foram obtidos por Bikker et al. (1996) e Ellis et al. (1996).

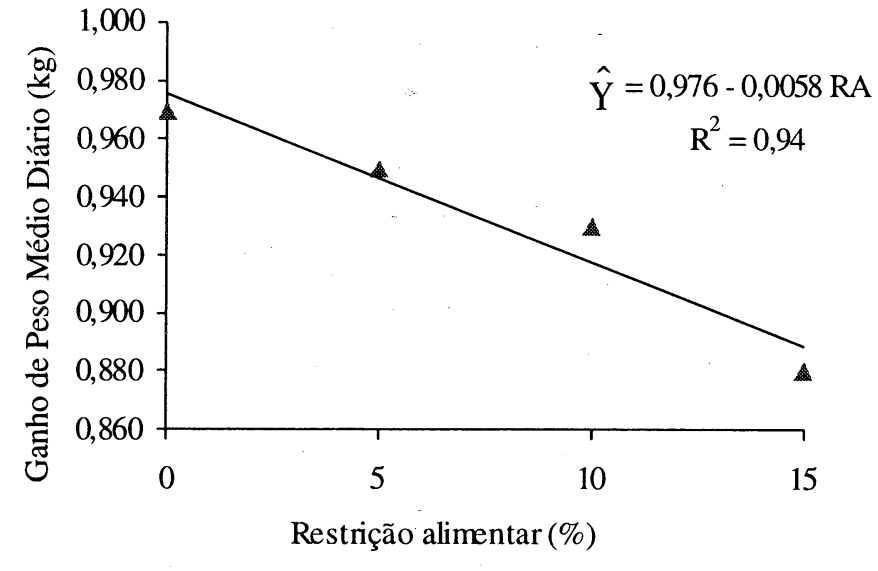

Figura 2 - Ganho de peso médio de suínos em terminação em função do nível de restrição alimentar

O consumo de energia líquida diminuiu linearmente com aumento na restrição alimentar, conforme pode ser observado na Figura 3.

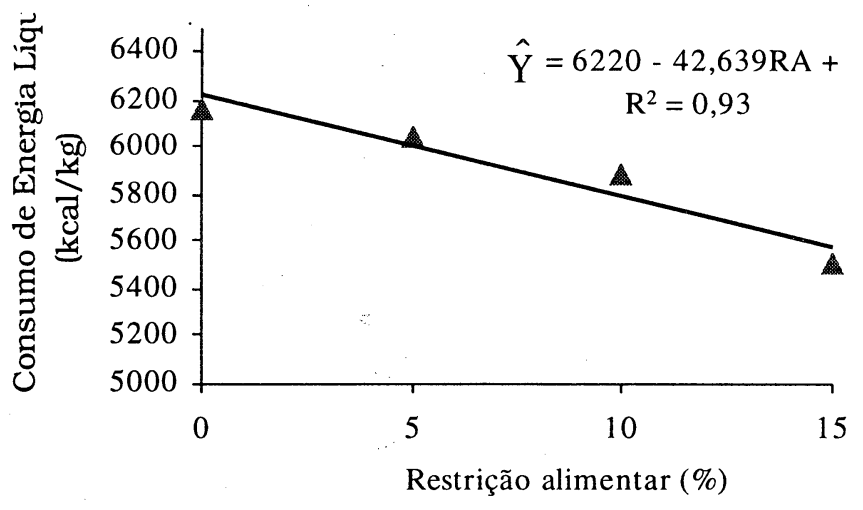

Figura 3 - Consumo de energia líquida de suínos em terminação em função do nível de restrição alimentar

Com relação à conversão de energia líquida em peso corporal, os resultados estão de acordo com aqueles obtidos por Ramaekers et al. (1996) e Ramaekers et al. (1997), nos quais 
não foi observada diferença na taxa de conversão de energia, pois os suínos sob restrição alimentar utilizaram a energia com maior eficiência para crescimento cárneo, enquanto os suínos alimentados à vontade tiveram crescimento mais rápido e menor demanda energética para mantença e para ganho de peso.

Observou-se que a espessura média de toucinho reduziu linearmente com o aumento na restrição alimentar (Figura 4), concordando com resultados obtidos por Friesen et al. (1994), Bikker et al. (1996), Quiniou et al. (1996), Ramaekers et al. (1996) e Ellis et al. (1996), que concluíram que animais alimentados à vontade ou com maior nível alimentar depositam proporcionalmente mais gordura e menos músculo na carcaça do que aqueles alimentados com um baixo nível alimentar ou sob restrição alimentar.

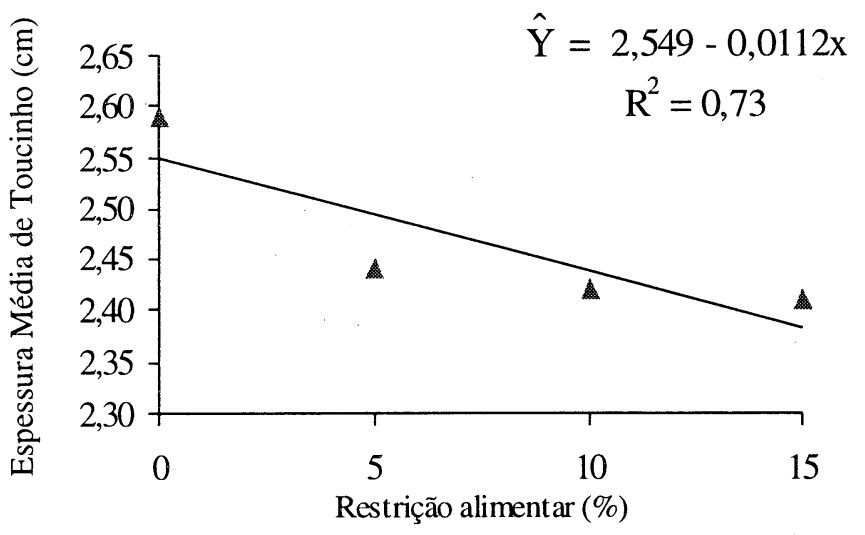

Figura 4 - Espessura média de toucinho de suínos em terminação em função do nível de restrição alimentar.

Haydon et al. (1989) concluíram que, restringindo o consumo alimentar diário em $15 \%$ e mantendo o consumo adequado de proteína, haveria redução no conteúdo de gordura na carcaça em $29 \%$ sem diminuição da quantidade e qualidade de carne, e que a redução maior no consumo melhoraria a qualidade de carcaça. Entretanto, poderia não ser economicamente viável, por prolongar o período de terminação, uma vez que os animais demandariam mais tempo para atingir o peso adequado para abate.

Os resultados de desempenho dos suínos em terminação alimentados com diferentes níveis de energia líquida da dieta podem ser observados na Tabela 4.

O nivel de energia da dieta afetou $(P<0,05)$ o peso final dos suínos, com maior peso final os animais submetidos a dieta com maior nível de energia líquida. Embora não tenha ocorrido diferença significativa em relação ao consumo médio diário, os animais alimentados com o maior nível de energia líquida tiveram significativamente maior ganho de peso médio diário. líquida (EL) da dieta
Estes resultados discordam daqueles obtidos por Bertechini et al. (1986), que avaliaram três níveis de energia digestível de $3.150,3.350$ e $3.550 \mathrm{ED} \mathrm{kcal} / \mathrm{kg}$ para suínos em crescimento e terminação e observaram que o aumento na energia dietética causou efeito depressivo no consumo de ração, não havendo diferença significativa em ganho de peso diário.

Resultados semelhantes foram obtidos por Oliveira et al. (1986) que avaliando diversos níveis de energia na dieta para suínos em crescimento e em terminação, em condições e locais diferentes, observaram que o ganho de peso dos suínos foi semelhante entre os níveis de energia nas dietas avaliadas.

O consumo de energia líquida foi afetado significativamente entre níveis de energia estudados, havendo aumento no consumo com aumento no nível de energia, porém a conversão de energia líquida em peso corporal não diferiu significativamente nos níveis de energia estudados. Bertechini et al. (1986) não verificaram efeito significativo dos níveis de energia da dieta sobre a eficiência da utilização de energia. Oliveira et al. (1986), avaliando dois níveis de energia digestível de 3.220 e $3.560 \mathrm{kcal} E D / \mathrm{kg}$ de ração para suínos também não observaram diferença significativa dos níveis de energia sobre o consumo de energia e conversão de energia em peso corporal.

De acordo com Castell et al. (1994), o conteúdo de energia da dieta influencia o consumo alimentar de suínos em crescimento - terminação e a restrição no consumo diário de energia pode ser fundamental para os suínos alcançarem crescimento máximo.

Observou-se maior espessura de toucinho $(P<0,05)$ nos animais que receberam dieta com maior nível de energia líquida. Estes resultados estão de acordo com aqueles de Oliveira e Teixeira Filho (1984) em que animais alimentados com dieta com maior nível de energia apresentaram maior espessura de toucinho que naqueles alimentados com dieta com menor nível de energia. Segundo Quiniou et al. (1996), o aumento no nível de energia da dieta está associado com o aumento linear na deposição de gordura. No entanto,

Tabela 4 - Desempenho de suínos em terminação em função do nível de energia

\begin{tabular}{|c|c|c|c|c|c|}
\hline \multirow[b]{2}{*}{ Parâmetro } & \multirow[b]{2}{*}{ Unidade } & \multicolumn{2}{|c|}{ EL da dieta $(\mathrm{Kcal} / \mathrm{kg})$} & \multirow[b]{2}{*}{ Média } & \multirow[b]{2}{*}{$\mathrm{CV}(\%)$} \\
\hline & & 2083 & 2252 & & \\
\hline Peso inicial & $\mathrm{kg}$ & 57,04 & 58,47 & 57,75 & 5,51 \\
\hline Peso final & $\mathrm{kg}$ & 91,85 & 95,81 & * & 3,29 \\
\hline Consumo médio de ração & $\mathrm{kg} / \mathrm{d}$ & 2,72 & 2,73 & 2,72 & 7,17 \\
\hline Ganho de peso médio & $\mathrm{Kg} / \mathrm{d}$ & 0,89 & 0,98 & * & 8,50 \\
\hline Consumo de energia líquida & $\mathrm{Kcal} / \mathrm{kg}$ & 5668,40 & 6131,94 & * & 7,17 \\
\hline Conversão de energia & $\mathrm{kcal} / \mathrm{kg}$ & 6393,52 & 6275,21 & 6334,36 & 5,20 \\
\hline Espessura média de toucinho & $\mathrm{cm}$ & 2,35 & 2,59 & * & 5,40 \\
\hline
\end{tabular}

* Significativo $(P<0,05)$ pelo teste de $F$

Bertechini et al. (1986) não observaram influência do nível de energia na dieta na espessura de toucinho.

Os valores médios dos parâmetros de desempenho dos animais em função do sexo podem ser observados na Tabela 5. 
Tabela 5 - Desempenho de suínos em terminação, em função do sexo

\begin{tabular}{|c|c|c|c|c|c|}
\hline \multirow[t]{2}{*}{ Parâmetro } & \multirow[t]{2}{*}{ Unidade } & \multicolumn{2}{|c|}{ Sexo } & \multirow{2}{*}{ Média } & \multirow{2}{*}{$\begin{array}{l}C V \\
(\%)\end{array}$} \\
\hline & & Macho & Fêmea & & \\
\hline Peso inicial & $\mathrm{kg}$ & 58,53 & 57,75 & 58,14 & 5,51 \\
\hline Peso final & $\mathrm{kg}$ & 94,21 & 93,45 & 93,83 & 3,29 \\
\hline Consumo médio de ração & $\mathrm{kg} / \mathrm{d}$ & 2,83 & 2,63 & * & 7,17 \\
\hline Ganho de peso médio & $\mathrm{kg} / \mathrm{d}$ & 0,943 & 0,922 & 0,93 & 8,50 \\
\hline Consumo de energia líquida & $\mathrm{Kg} / \mathrm{kg}$ & 6086,87 & 5713,47 & * & 7,17 \\
\hline Conversão de energia & $\mathrm{Kcal} / \mathrm{kg}$ & 6476,95 & 6191,78 & * & 5,20 \\
\hline Espessura média de toucinho & $\mathrm{cm}$ & 2,52 & 2,42 & * & 5,40 \\
\hline
\end{tabular}

* Significativo $(P<0,05)$ pelo teste de $F$

Não foram observados efeitos significativos $(P>0,05)$ do sexo em relação ao peso final, ganho de peso médio diário, peso de carcaça. Em relação ao peso final, estes resultados discordam de Souza et al. (1997), que observaram que fêmeas apresentaram peso final inferior aos machos castrados.

Observou-se que machos castrados consumiram mais ração do que as fêmeas, portanto, tiveram maior consumo de energia líquida, porém, não houve diferença significativa no ganho de peso médio diário entre os sexos, o que explica a melhor conversão de energia líquida para as fêmeas em relação aos machos castrados.

Em relação ao consumo médio diário, os resultados obtidos por Bertechini et al. (1986), Pereira et al. (1987), Hammel et al. (1993), Friesen et al (1994), Castell et al. (1994) e Moeller et al. (1998) concordam com os resultados obtidos neste trabaIho uma vez que, em geral, os autores citados também observaram diferença significativa para consumo diário, porém observaram maior ganho de peso diário para machos castrados, em relação a fêmeas, diferindo do que foi observado neste trabalho.

Hammel et al. (1993) e Castell et al. (1994) observaram que machos castrados apresentaram maior ganho de peso do que fêmeas e atingiram peso de abate alguns dias antes das fêmeas, o que também foi observado neste trabalho, para machos castrados de algumas unidades experimentais, os quais atingiam o peso de abate, em média, sete dias antes das fêmeas sob o mesmo tratamento, enquanto Hyun et al. (1997) não observaram diferença significativa entre os sexos para consumo diário, e que o ganho de peso diário foi maior para os machos.

Foram observados um menor consumo de energia e melhor conversão de energia em peso corporal em fêmeas do que para os machos castrados $(P<0,05)$. Estes resultados estão de acordo com os de Bertechini et al. (1986), que observaram que em conseqüência do menor consumo de alimentos pelas fêmeas, estas apresentaram menor consumo de energia e melhor conversão de energia.

Em relação à espessura de toucinho, os resultados estão de acordo com aqueles observados na literatura, nos quais as fêmeas apresentam menor espessura de toucinho e carcaça de qualidade superior, com maior percentual de carne, do que machos castrados (Castell et al., 1994; Friesen et al., 1994; Ellis et al., 1996; Souza et al., 1997; Moeller et al., 1998; Fialho et al., 1998 e Gonçalves et al., 1999).

\section{Agradecimentos}

Ao Sr. Manoel Teixeira Lopes, proprietário da Fazenda Penalva, pelo financiamento da pesquisa, aos funcionários da Fazenda Penalva pela colaboração na realização dos trabalhos desenvolvidos nesta pesquisa e à Fundação de Amparo à Pesquisa do Estado do Rio de Janeiro pela concessão da bolsa de Mestrado.
Suínos machos castrados tem maior espessura média de toucinho devido ao fato de depositarem gordura mais rápido do que as fêmeas (Moeller et al., 1998).

Esta diferença entre machos castrados e fêmeas pode ser explicada pelo efeito hormonal, uma vez que as fêmeas possuem os hormônios sexuais que têm efeito anabólico para proteína, os quais estão ausentes nos machos devido à castração.

Fialho et al. (1998), avaliando planos de nutrição com níveis crescentes de proteína para dois genótipos diferentes, observaram que, indepenram qualidade de carcaça superior à de machos castrados.

Segundo Leymaster e Mersmann (1991), suínos machos castrados alimentados à vontade e com consumo de energia aumentando de 5,50 para $6,44 \mathrm{kcal} /$ dia de EM, em média, durante o período de crescimento-terminação, têm um menor conteúdo de carne magra na carcaça do que fêmeas, ao mesmo peso de abate. O conteúdo relativamente baixo de carne magra dos machos castrados quando comparados às fêmeas está associado com baixa proporção entre deposição de proteína e gordura que se altera de 1:8 para 1:3 e com baixo nível de deposição de proteína que se altera de 70 para 120 g/dia (Campbell e Taverner, 1988).

Observou-se interação significativa $(P<0,05)$ entre o nível de energia líquida da dieta e sexo para conversão alimentar, como pode ser observado na Tabela 6.

Para o nível de energia líquida da dieta de $2.252 \mathrm{kcal}$ EL/ $\mathrm{kg}$ de ração não foi observada diferença significativa na conversão o nível de energia de $2.083 \mathrm{kcal}$ EL $/ \mathrm{kg}$ de ração, foi observada melhor conversão alimentar para as fêmeas que para machos castrados.

Tabela 6 - Conversão alimentar de suínos em terminação em função da interação entre energia líquida da dieta (kcal/ $\mathrm{kg}$ ) e sexo

\begin{tabular}{l|c|c|c|c|c}
\hline \multirow{2}{*}{ Parâmetro } & \multirow{3}{*}{ Unidade } & \multicolumn{4}{|c}{ Energia líquida (kcal/kg) } \\
\cline { 3 - 6 } & & $2.083 \mathrm{kcal} \mathrm{EL/kg}$ & $2.252 \mathrm{kcal}$ EL/kg \\
\cline { 3 - 6 } & & Machos & Fêmeas & Machos & Fêmeas \\
\hline $\begin{array}{l}\text { Conversão } \\
\text { Alimentar }\end{array}$ & $\mathrm{kg} / \mathrm{kg}$ & $3,19 \mathrm{~b}$ & $2,81 \mathrm{a}$ & $2,95 \mathrm{a}$ & $2,77 \mathrm{a}$ \\
\hline
\end{tabular}

'Médias seguidas de letras diferentes na mesma linha e para mesmo sexo diferem significativamente $(P<0,05)$, pelo teste $F$

\section{Conclusões}

O aumento na restrição alimentar resultou em diminuição do ganho de peso, sem afetar a conversão alimentar. Os machos castrados e fêmeas apresentaram ganho de peso semelhante. $O$ aumento no nível de energia líquida da dieta resultou em aumento no ganho de peso e melhoria na conversão alimentar. dentemente do plano de nutrição e do genótipo, fêmeas tivealimentar entre machos castrados e fêmeas. Entretanto, para 


\section{Referências}

BERTECHINI, A. G, ROSTAGNO, H.S., PEREIRA, J. A. A. et al. Níveis de energia para suínos nas fases de crescimento e terminação. Rev. Soc. Bras. de Zootec., v. 15, n. 6, p. 452-460, 1986.

BIKKER, P., VERSTEGEN, M.W.A., KEMP, B. et al. Performance and body composition of finishing gilts ( 45 to 85 kilogramas) as affected by energy intake and nutrition in earlier life: I. Growth of the body and body components. J. Anim. Sc., v. 74, p. 806-816, 1996.

CAMPBELL, R.G., TAVERNER, M.R. Genotype and sex efeccts on the relationship between energy intake and protein deposition in growing pigs. J. Anim. Sc., v. 66, p. 676-686, 1988.

CARNINO, F. Efeito de fatores fisiológicos e nutricionais sobre a qualidade da carcaça de suínos. SIMPÓSIO LATINO-AMERICANO DE NUTRIÇÃO DE SUÍNOS, 1994, Campinas, SP. Anais..., Campinas: CBNA, p.137-157.

CASTELL, A.G., CLIPLEF, R.L., POSTE-FLYNN, G. et al. Performance, carcass and pork characteristics of castrates and gilts self-fed diets differing in protein content and lysine:energy ratio. Can J. Anim. Sc., v. 74, p. 519-528, 1994.

DONKER, R.A., DEN HARTOG, L.A., BRASCAMP, E.W. et al. Restriction of feed intake to optimize the overall performance and composition of pigs. Livest.Prod. Sc., v. 15, p. 353-365, 1986.

ELLIS, M., WEBB, A.J., AVERY, P.J. et al. The influence of terminal sire genotype sex, slaughter weight, feeding regime and slaughter-house on growth performance, and carcass and meat quality in pigs and on the organoleptic properties of fresh pork. Anim. Sc., v. 62, p. 521-530, 1996.

FIALHO, E.T., OLIVEIRA, A.I.G., LIMA, J.A.F. et al. Influência de planos de nutrição sobre as características de carcaça de suínos de diferentes genótipos abatidos entre 80 e 120kg. Rev. Bras. Zootec, v. 27, n. 6, p.1140-1146, 1998.

FRIESEN, K.G., NELSSEN, J.L., UNRUH, J.A., et al. Effects of the interrelationship between genotyppe, Sex, and dietary lysine on growth performance and carcass composition in finishing pigs fed to either 104 or 127 kilogramas. J. Anim. Sc., v. 72, p. 946-954, 1994.

GILES, L.R. Effect of nutrition on carcass quality. Animal Production in Australia. Proc. Aust. Soc. Anim. Prod, v. ,18, p. 92-94, 1990.

GONÇALVES, T.M., BERTECHINI, A.G., OLIVEIRA, A.I.G., et al. Lisina, energia e sexo sobre as características de carcaças de suínos hibrídos modernos. In: XXXVIREUNIÃO ANUAL DA SOCIEDADE BRASILEIRA DE ZOOTECNIA, 36., 1999, Porto Alegre, RS, Anais..., Porto Alegre: SBZ, p. 331.

HAMMELL, K.L., LAFOREST, J.P. DUFOUR, J.J. Evaluation of the growth performance and carcass characteristics of commercial pigs produced in Quebec. Can. J. Anim. Sc., v. 73, p. 495-508. 1993.

HAYDON, K.D., TRANKSLEY, T.D.Jr., KNABE, D.A. Performance and carcass composition of limited fed finishing swine. J. Anim. Sc., v. 68, n. 8, p. 1916-1925, 1989.
HYUN,Y., ELLIS, M., MCCKEITH, F.K., et al. Feed intake pattern of grouphoused growing-finishing pigs monitored using a computerized feed intake recording system. J. Anim. Sc., v. 75, p.1.443-1.451. 1997.

LEYMASTER, K.A., MERSMANN, H.J. Effect of limited feed intake on growth of subcutaneous adipose tissue layers and carcass composition in swine. J. Anim. Sc., v. 64, p. 2837-2843, 1991.

MINISTÉRIODAAGRICULTURA-SISTEMADETIPIFICAÇÃODECARCAÇA SUÍNA. Portaria nº 221, de 22 de setembro de 1981.

MOELLER, S.J., CHRISTIAN, L.L., GOODWIN, R.N. Development of adjustament factors for backfat and loin muscle area from serial realtime ultrasonic measurements on purebred lines of swine. J. Anim. Sc., v. 76, p. 2.008-2.016. 1998.

NATIONAL RESEARCH COUNCIL. Nutrient requirement of pigs. 10th Edition Rev. Washington: National Academic Press. 1998. 189 p.

NOBLET, J. Utilização digestiva e metabólica da energia de rações de suínos: Novas propostas para um sistema de energia líquida. In: SIMPÓSIO LATINO-AMERICANO DE NUTRIÇÃO DE SUÍNOS EAVES. 1995, Campinas, SP. Anais... Campinas, CBNA, p. 83-101, 1995.

, HENRY, Y. Energy evaluation systems for pig diets: a review. Livest. Prod. Sc., v. 36, p. 121-141, 1993.

FORTUNE,.H., SHI, X.S., DUBOIS, S. Prediction of net energy of feeds for growing pigs. J. Anim. Sc., v. 72, p. 344-354, 1994.

OLIVEIRA, A.I.G., TEXEIRA FILHO, J.R., Níveis energéticos e protéicos na alimentação de suínos para abate. Rev. Soc. Bras. Zoot., v. 13, n. 3 , p. 324-333, 1984.

BARBOSA, M.A., SOUTO, P.R.L. Condições climáticas e níveis de energia e proteína/lisina para suínos. Rev. Soc. Bras. Zoot., v. 15, n. 1, p. 36-47, 1986.

PEREIRA, J.A., CUNHA, J.L., COSTA, P.M.A., et al. Efeitos da restrição alimentar sobre o desempenho de suínos em crescimento-terminação. Rev. Soc. Bras. Zoot., v. 16, n. 1, p. 111-119, 1987.

QUINIOU, N., DOURMAD, J.Y., NOBLET, J. Effect of energy intake on the performance of different types of pig from 45 to $100 \mathrm{~kg}$ body weight. I. Protein and lipid deposition. Anim. Sc., v. 63, p. 77-288, 1996. RAMAEKERS, P.J.L., SWINKELS, J.W.G.M., HUISKES, J.H. et al.. Performance and carcass traits of individual pigs housed in groups as affected by ad libitum and restricted feeding. Livest. Prod. Sc., v. 47, p. 43-50, 1996.

, et al. Effectiveness of a pair-gain feeding strategy for individually fed, group-housed finishing pigs. J. Anim. Sc., v. 75, p.2.6912.696, 1997.

SOUZA, R.M., ANTUNES, C.F., OLIVEIRA, A.I., et al. Características e rendimentos de carcaça de suínos obtidos a partir de três diferentes genótipos. Rev. Assoc. Bras. Vet. Espec. Suínos, v. 2, p. 47-51, 1997.

UNIVERSIDADE FEDERALDE VIÇOSA - SAEG - Sistema de Análises Estatísticas e Genéticas Versão 5.0. Viçosa, MG. 1993. 